УДК 372.881.111.1

\title{
ОСОБЕННОСТИ ОБУЧЕНИЯ ИНОЯЗЫЧНОМУ НАУЧНОМУ ПИСЬМЕННОМУ ДИСКУРСУ МАГИСТРАНТОВ
}

\author{
Кисметова Галия Нагимовна \\ к.П.н., доцент \\ Кондудаева Динара Жексемальевна \\ Западно-Казахстанский инновационный- \\ технологический университет
}

\begin{abstract}
Аннотация: В статье нами была рассмотрена потребность магистрантов в овладении иностранной письменной научной речью, что открывает актуальность проблемы разработки новых подходов обучения с учетом последних тенденций в смежных с методикой обучения иностранным языкам областях знания. Был предложен алгоритм обучения, которые состоит из трех этапов, а также рассмотрены результаты эксперимента. В конце статьи мы сделали выводы по поводу обоснованности выбора предложенной методики обучения.
\end{abstract}

Ключевые слова: Иностранный язык, статья, иноязычный письменный дискурс, магистранты, обучение магистрантов, иностранные статьи, методика обучения.

\section{FEATURES OF TEACHING FOREIGN LANGUAGE WRITTEN SCIENTIFIC DISCOURSE TO MASTER STUDENT}

\section{Khismetova Galiya Nagimovna Kondudayeva Dinara Zheksemalevna}

\begin{abstract}
In the article, we have considered the need for undergraduates to master foreign written scientific speech, which opens up the relevance of the problem of developing new approaches to teaching, taking into account the latest trends in areas of knowledge related to the methodology of teaching foreign languages. A learning algorithm was proposed, which consists of three stages, and the results of the
\end{abstract}




\section{МЕЖДИСЦИПЛИНАРНЫЙ ВЕКТОР РАЗВИТИЯ СОВРЕМЕННОЙ

experiment were considered. At the end of the article, we made conclusions about the validity of the choice of the proposed training method.

Key word: Foreign language, article, foreign language written discourse, undergraduates, training of undergraduates, foreign articles, teaching methods.

В последние годы наблюдается стремительное развитие науки и техники, что предъявляет новые требования для специалистов. Одним из таких требований можно назвать владение иноязычным научным дискурсом.

Данная потребность стала стимулом для разработки специальных методов для обучения магистрантов. Алгоритм обучения состоит их трех этапов, которые можно увидеть в таблице 1 [1].

Таблица 1

3 основных этапа по подготовке к написанию иноязычных статей магистрантами

\begin{tabular}{|c|c|}
\hline Этап & Описание \\
\hline 1. Анализ образца текста & $\begin{array}{l}\text { Ознакомление с организационным } \\
\text { форматом научных статей при помощи } \\
\text { образцов, которые предлагает } \\
\text { преподаватель. } \\
\text { Анализ риторической структуры статьи- } \\
\text { образца } \\
\text { по типу дискурса «Проблема и ее } \\
\text { решение», анализ лексико- } \\
\text { грамматических особенностей научных } \\
\text { статей, свойств научного дискурса }\end{array}$ \\
\hline $\begin{array}{l}\text { 2. Написание статей, которые состоят } \\
\text { из нескольких абзацев (по одному } \\
\text { абзацу на каждый раздел (введение, } \\
\text { методы и материалы, } \\
\text { результаты и обсуждения, заключение) } \\
\text { под руководством преподавателя и на } \\
\text { основе предоставляемых } \\
\text { им данных }\end{array}$ & $\begin{array}{l}\text { Ориентировка: } \\
\text { - планирование, } \\
\text { - составление наброска, } \\
\text { - пересмотр наброска, } \\
\text { - редактирование, } \\
\text { - подготовка финальной версии. }\end{array}$ \\
\hline $\begin{array}{l}\text { 3. Написание статей с использованием } \\
\text { личных данных магистранта }\end{array}$ & $\begin{array}{l}\text { Ориентировка: } \\
\text { - планирование, } \\
\text { - составление наброска, } \\
\text { - пересмотр наброска, } \\
\text { - редактирование, } \\
\text { - подготовка финальной версии }\end{array}$ \\
\hline
\end{tabular}




\section{МЕЖДИСЦИПЛИНАРНЫЙ ВЕКТОР РАЗВИТИЯ СОВРЕМЕННОЙ НАУКИ: ТЕОРИЯ, МЕТОДОЛОГИЯ, ПРАКТИКА}

Обучение может производиться как дополнительная дисциплина в изучении иностранного языка .

В результате освоения данной дисциплины магистр должен овладеть общекультурными и профессиональными компетенциями: умение свободно использовать русский и иностранный языки как средство делового общения и написания иноязычных статей, овладеть навыками редактирования и перевода профессиональных текстов, научиться сотрудничать, разрешать конфликты, писать деловые письма.

Дисциплина должна содержать следующие принципы:

1. принцип сознательности,

2. принцип активности,

3. принцип системности,

4. принцип функциональности,

5. принцип деятельностного характера обучения,

6. принцип поэтапности в формировании речевых навыков и умений принцип личностной направленности обучения,

7. принцип контекстного обучения (профессиональной направленности),

8. принцип коммуникативности,

9. принцип взаимосвязанного обучения видам письменной деятельности [2].

Текущий контроль осуществляется после каждой темы, магистранты должны правильно переводить предложения с русского на иностранный язык, используя активную лексику и изученную грамматику. Тестирование должно позволять преподавателю получить достаточно полные данные об уровне знаний, умений по предмету и отношении к обучению, степени познавательной активности и сознательности мастера. [3, с.32].

Промежуточный контроль осуществляется письменно (перевод текста на общенаучные и профессиональные темы) и предусматривает проверку уровня владения чтением профессиональной литературы, так как требует от студента набора знаний и умений. В письменной форме студент демонстрирует практические знания, позволяющие определить уровень владения переводом профессиональной литературы [4, с.11].

Так, например, в рамках этого типа контроля студенты должны сдавать 6 переводов научных текстов, общий объем которых составляет 75000 символов. 


\section{МЕЖДИСЦИПЛИНАРНЫЙ ВЕКТОР РАЗВИТИЯ СОВРЕМЕННОЙ НАУКИ: ТЕОРИЯ, МЕТОДОЛОГИЯ, ПРАКТИКА}

Итоговый контроль проводится в форме экзамена в конце 1 и 2 семестра по результатам текущих академических достижений, письменных переводов и итогового представления результатов курсовой работы или магистерской диссертации.

Таким образом, в соответствии с целями и задачами освоения данной дисциплины студенты должны уметь следующее:

1. осуществлять межкультурное межличностное и профессионально ориентированное общение (рецептивные и продуктивные виды речевой деятельности) на основе эквивалентных языковых единиц, терминов и реалий страны изучаемого языка;

2. правильно использовать в речи лексические, грамматические и синтаксические средства для формирования высказываний в соответствии с типом текста и его жанром в соответствующей профессиональной сфере; устанавливает, поддерживает и прекращает контакт с партнером по общению на иностранном языке;

3. решать межличностные и деловые задачи в профессиональной сфере.

В учебном заведении «Уральский гуманитарный колледж» мною был проведен эксперимент на кафедре «Иностранный язык: два иностранных языка». Студенты в экспериментальной группе обучались по системе, описанной в начале этой статьи [4].

Экспериментальная работа включала 2 этапа: предэкспериментальный (проверка интеллекта и исследовательская работа и тестирование), сам эксперимент, который включал три подэтапа (анализ образца статьи, написание мини-статьи студентами на иностранном языке под руководством преподавателя и на основе предоставленных из его данных), написание статьи с использованием собственных данных.

Для оценки сформированности навыков разработана шкала оценки, включающая такие параметры, как риторическое структурирование, содержание, лексико-грамматическое оформление, орфография и пунктуация, связность текста.

Проведено сравнение результатов, полученных на последнем этапе экспериментальной тренировки в экспериментальной и контрольной группах студентов. И-критерий Манна-Уитни использовался для установления точного наличия статистически значимых различий между уровнем развития письменной компетенции на иностранном языке в сфере научного общения в 


\section{МЕЖДИСЦИПЛИНАРНЫЙ ВЕКТОР РАЗВИТИЯ СОВРЕМЕННОЙ НАУКИ: ТЕОРИЯ, МЕТОДОЛОГИЯ, ПРАКТИКА}

экспериментальной и контрольной группах. С помощью данного критерия было доказано, что студенты экспериментальной группы превосходят студентов контрольной группы по уровню сформированности иноязычной компетенции в письменном дискурсе в контексте исследования, что показывает эффективность предложенной методики обучения иностранному письменному научному дискурсу на основе материала из научной статьи.

Тестирование выявило следующие проблемы:

1. Стандартизированная композиционная структура научной статьи нечетко прослеживалась в $75 \%$ работ. Это указывало на то, что композиционный формат научной статьи, который был предназначен для студентов старших курсов, не был им знаком. Только в $25 \%$ работ была сделана попытка приблизиться к заданному композиционному формату.

2. В $85 \%$ статей наблюдалось отсутствие риторической структуры дискурса, то есть не было соблюдено правило «проблема-решение».

3. В половине статей отсутствовал логический порядок изложения.

4. Около $20 \%$ не использовали научную речь.

5. Синтаксический и грамматических ошибок в работах практически не было, что можно считать отличной работой редакторов.

Максимальное количество баллов, которое можно набрать - 50 .

В диаграмме можно увидеть количество баллов, которое набрали студенты.
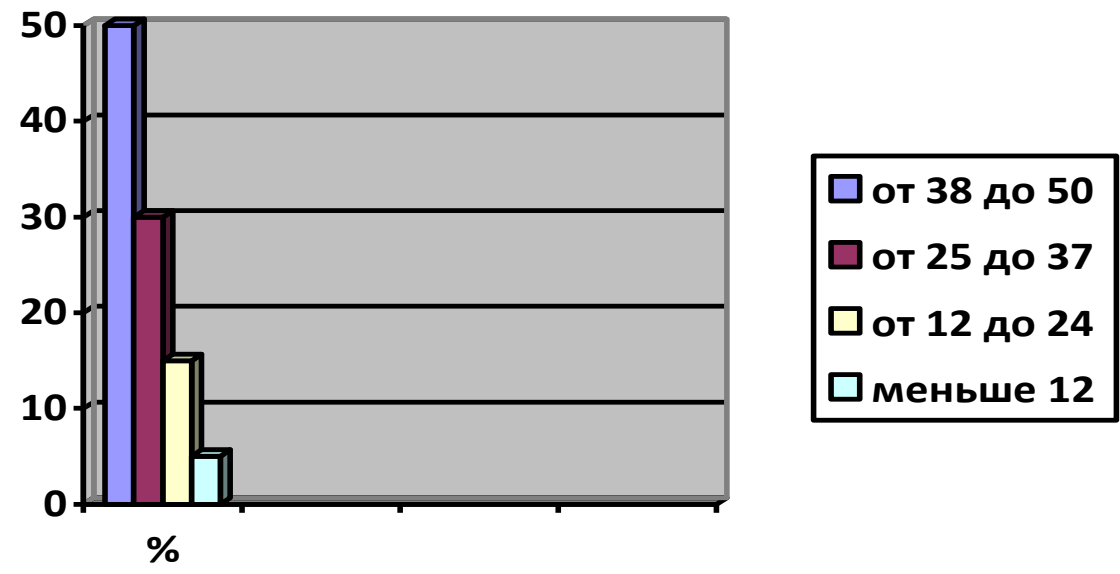

Рис. 1. Количество набранных баллов студентами в \% 


\section{МЕЖДИСЦИПЛИНАРНЫЙ ВЕКТОР РАЗВИТИЯ СОВРЕМЕННОЙ НАУКИ: ТЕОРИЯ, МЕТОДОЛОГИЯ, ПРАКТИКА}

Из диаграммы можно увидеть, что большинство студентов набрали хорошие баллы. Основные проблемы выявлены следующие:

1. Незнания студентов о композиционных структурах статей.

2. Не умение составлять риторическую структуру в статье.

3. Не умение создавать речевую целостность в излагаемом материале.

4. Недостаточность знаний о лексико-грамматических особенностях научных статей .

Таким образом, можно сделать вывод, что предложенный трехэтапный алгоритм является достаточно эффективным средством обучения письменному иностранному научному дискурсу не только магистрантов ,но и студентов колледжа .

\section{Список литературы}

1. Проблемы национальных особенностей преподавания иностранных языков и культур, международный сборник научных трудов. Тамбов, 2014

2. Основные принципы обучения иностранному языку по направлению магистратуры в свете новых образовательных стандартов [Электронный pecypc]//URL: http://human.snauka.ru/2015/01/9257 (Дата обращения: 26.11.2020)

3. Друцко Н.А. Кейс-технологии и проектное обучение как инструмент формирования межкультурной компетенции у студентов вуза // Научный журнал Общество: социология, психология, педагогика. Выпуск 1. 2014. - С. 79-83.

4. Степанова М.М. Современные подходы к обучению иностранному языку в магистратуре неязыкового вуза // Научно-технические ведомости СПбГПУ. Гуманитарные и общественные науки. 2/111/2010. - С. 109-114. 